\title{
Use of Role-playing Exercises in Teaching Undergraduate Astronomy and Physics
}

\author{
Paul J. Francis ${ }^{1,2}$ and Aidan P. Byrne ${ }^{1,3}$ \\ ${ }^{1}$ Department of Physics and Theoretical Physics, \\ Faculty of Science, Australian National University, \\ Canberra, ACT 0200, Australia \\ paul.francis \& aidan.byrne@anu.edu.au \\ ${ }^{2}$ Joint appointment with the Research School of Astronomy and Astrophysics \\ ${ }^{3}$ Joint appointment with the Department of Nuclear Physics, \\ Research School of Physical Sciences and Engineering
}

Received 1998 September 3, accepted 1999 March 10

\begin{abstract}
The use of role-playing exercises in the teaching of university astronomy and physics can enliven lectures, deepen student understanding and dramatically increase the level of classroom interaction. A series of case studies is presented, illustrating the nature of this technique, its advantages and some of its pitfalls. Several ready-to-run exercises are included.
\end{abstract}

Keywords: miscellaneous — undergraduate teaching

\section{Introduction}

Anybody who has done a course at a corporate training centre will have been struck by the dramatic contrast between their teaching methods and those generally employed in undergraduate astronomy and physics courses. In most undergraduate courses, the teacher stands at the front presenting a stream of information, which the students copy down. Occasionally questions are asked, but the students are essentially passive throughout. In corporate training centres, most classroom time is devoted to role-playing simulations, business games and discussion sessions. Students are active throughout; the students speak for more of the time than their teachers.

Why do corporations spend big money on such unorthodox teaching methods? Abundant research shows that students taught in conventional lectures, even those who perform very well in conventional assessment, are often quite unable to apply their knowledge effectively in real-world situations. Conventionally taught students tend to rote-learn: they fail to integrate their new knowledge into their prior assumptions, and they rarely think through the implications of what they learn. For these reasons, increasing numbers of universities are experimenting with teaching techniques that present information to students in more lifelike ways, and which encourage the integration of a student's knowledge.

We have recently been experimenting with applying some of these corporate techniques to undergraduate astronomy and physics lectures at the
Australian National University (ANU). This paper is a case study of some of our first experiments. We have yet to conduct a quantitative analysis of the effects of these exercises, although student feedback was very supportive of the approach. Nonetheless, we hope that an account of these techniques, and some of the lessons learned, may be of value to other lecturers looking for ways to enliven their lectures. These techniques can be seen as a variant of interactive tutorial teaching methods.

After briefly reviewing the literature on group learning in Section 2, we present a detailed case study of a role-playing exercise used in an astronomy lecture in Section 3. We then briefly discuss other role-playing exercises (Section 4) before giving a summary. Copies of all the exercises we used are included in the electronic version of this paper as appendices.

\section{Educational Theory}

Lectures are a highly effective method of transferring information from the notes of the lecturer to the notes of the students (though not as effective as photocopiers and textbooks). A large body of educational research, has shown however, that very little of this information lodges in the minds of the students en route (e.g. Ramsden 1992). This is obvious to anyone marking undergraduate exam scripts.

Surveys of students, particularly in large first-year physics introductory courses, reveal an extremely bleak picture (e.g. Loss \& Zadnik 1994). The 
mental state of students in a typical lecture is very passive: information washes over them, without penetrating. Students complain that classes are antisocial: astronomy and physics are seen as individual activities, rather than the social enterprises they actually are.

The generally accepted solution is to get the students to learn collaboratively, in groups. An enormous body of quantitative research testifies to the power and effectiveness of these methods (e.g. Matthews 1996), which are widely used in many disciplines worldwide. In physics, the book by Mazur (1997) makes the case for such exercises very strongly, and provides an excellent collection of group exercises, ready to use. An extremely useful and practical guide to designing and troubleshooting group-learning activities is the article by Michaelson, Fink \& Black (1996). A more general guide is Errington (1997).

\section{Case Study: Solar System Formation Exercise}

The case study is of an attempt to teach the theory of solar system formation, using a competitive role-playing exercise, during lectures.

The aim of this exercise was to attempt to get every student in the class to actively think through what they were learning, right there in the lecture. The challenge was to achieve this while still covering material at the rate achieved in conventional lectures.

This exercise was trialled in the first semester of 1998. It was used with two classes of ANU first-year students. The first class, PHYS1003 'Astronomy and Planetary Science', was designed for students with no background in maths and physics, and had an enrolment of around 50 students. The second class, PHYS1005 'Introduction to Astrophysics', was designed for students with strong high-school maths and physics backgrounds (mainly intending physics majors), and had an enrolment of around 20 students.

\subsection{Pre-lecture Preparations}

The aim of the exercise was to teach students about the processes whereby a giant molecular cloud turns into a collection of stars, with associated planets. This involves the ideas of gravitational collapse, angular momentum support of accretion disks, nuclear fusion within the star, and particle agglomeration in the proto-planetary disk. This subject matter would normally have taken 2-3 lectures to cover.

The subject matter was broken into seven distinct parts, according to the physical process at work, and each piece was written up as a briefing paper, one page long. One briefing paper, for example, covered the role of gravity in the process of star and planet formation. It described how gravity will cause a gas cloud to shrink, and form lumps of mass $\sim 10^{30} \mathrm{~kg}$, which (in the absence of other forces) will continue to shrink, on a free-fall timescale (a number was quoted) until they form black holes. A second paper covered the role of angular momentum: it pointed out that if (for whatever reason) a gas cloud should shrink, its rotational speed will increase until centrifugal force balances gravity, which occurs on scales of $\sim 100$ AU. Other papers covered processes within accretion disks, the role of thermal pressure and cooling, condensation of grains, the collision of rocks to form planets, and the ignition of nuclear fusion in stars. The processes were necessarily simplified for a first-year class, but no more so than would have been required in a lecture.

\subsection{Lecture Preamble}

The lecture commenced with a five-minute slide show about giant molecular clouds, and about how stars and planets are thought to be born within them. A pre-exercise briefing was then carried out. The students were warned that they were about to take part in a role-playing exercise, designed to give them a feel for how the process of astronomical discovery works in practice:

'Pretend that this lecture is a research conference, and that you are the world's experts on star and planet formation, gathered together to try and figure out how one of these (a Malin slide of a giant molecular cloud) turns into several of these (NASA composite slide of sun and planets). Divide yourselves up into groups of three.'

Groups of two or three seem to be optimal for these exercises: any larger and the less articulate group members cease to play any effective part. Each group was given three copies of one of the briefing sheets. To add to the role-playing aspect, each group was also assigned to a real astronomical institute from somewhere around the world. We might say, for example:

'You three are experts in gas dynamics, from the University of Cambridge.'

The class was then addressed as a whole again.

'Each group of you are world experts in some branch of astrophysics. Just as in the real world, however, no single group can hope to know enough to solve this difficult problem alone. You will have to exchange information with many other groups to devise a complete picture, and win the undying glory of being first to figure out how stars and planets form. In the real world, whoever figured this out first would win Nobel prizes, fame, tenure, grants: all the good things in life! We cannot offer you that, but instead, whichever group comes up with a correct theory first will win this box of chocolates.

Take a few minutes to read your briefing sheets, and discuss what you have learned amongst yourselves. If you have any questions, come down and bug 
me. Once you've figured out your own areas of expertise, you will have to go out and exchange information with the other groups. Anything goes; you are allowed to form consortia, lie, cheat, steal, bribe: anything to figure out a complete picture. But bear in mind that unless you share information with other people, they will not share information with you. You are not allowed to show other groups your briefing papers: you must explain what is on them verbally. Your goal is to put all the information you will learn from the other groups together, to make a coherent theory of star and planet formation.

When you think you've figured out a theory that makes sense, complete with numbers and timescales, you must come down the front and present it to the class. The rest of the class will then vote on whether you deserve the chocolate. This, again, is just like the real world: you don't win by getting the right answer: you win by getting an answer that your peers will accept.

Once the exercise is over, I will hand out copies of the combined briefing sheets to all of you, and you will have to write-up the complete theory as part of an assignment. OK: if there are no questions, get going!'

\subsection{While the Exercise is Running}

The initial class response was generally stunned silence. Slowly groups read their briefing papers. Most classes had to be encouraged to start discussing their briefing papers, rather than just reading them individually in silence.

The lecturer then walked around the class, listening in on groups and offering advice, clarification and encouragement. At first, it was necessary to repeat over and over again that:

'You don't know enough to figure this out for yourselves.

Go out and talk to some of the other groups, and see if they know anything that helps fill in the gaps in your story'.

Once the first groups had started wandering around the class, accosting other groups and demanding to know what they were experts in, the whole class rapidly got the idea, and broke up into anarchy. Before running this exercise, we were worried that the class might just start gossiping, playing games, or otherwise mucking around, but in practice this was never the case; without exception the students seemed to focus on the exercise. The structure of the exercise was designed to stop groups from opting out of the discussion, as if a particular group was not very active, they would still be accosted regularly by other groups trying to find the answer to some problem, and this seemed to keep everyone continuously involved.

The classes contained one or two very keen amateur astronomers, and initially we were worried that they would know the answers and thus short-cut the exercise. We therefore required students to describe the full process, including timescales, as we doubted that any students could know this. This seemed to work; indeed the most knowledgeable students were particularly enthusiastic and commented that the exercise made them see this subject in a whole new light.

It rapidly became clear, from wandering around listening and helping, that certain points were confusing almost all the students. For example, the briefing paper on rotation had described the law of conservation of angular momentum, and how it means that as the cloud shrinks, it must spin faster, until rotation balances gravity. It transpired that many students got hung up on the following question: what happens if the cloud isn't spinning at all to begin with? Why should clouds spin, after all? We had never realised that this would be a sticking point; it was necessary to stop the exercise (by shouting and clapping loudly) and point out to the class that even the tiniest rotation would be amplified by the collapse process, and that the odds of anything having absolutely no rotation at all were tiny.

The atmosphere in class was wonderful: lots of excited chatter, students racing around interrogating each other and debating the science. Many of the conversations we listened to really sounded like academics in discussion:

'So, we've got this spinning cloud. What happens next? Is it dense enough to start forming grains, like you said?'

'But won't it turn into a black hole first?'

'Those idiots from Caltech won't share their information with us.'

Once the exercise was up and running, the lecturer proved to be almost redundant; the students were answering most of each other's questions without reference to him. Indeed, at the end of the lecture, it was difficult to persuade the students to leave.

\subsection{Ending the Exercise}

The students proved reluctant to conclude that they had a complete answer (even when they did), and so it was necessary to encourage the groups that seemed to be close to stand up and present their results. In most cases, the first group to present a theory turned out to be confused about some details, and were voted down by their peers. We were worried that some would take offence at this, so we insisted on a round of applause for their bold try. In practice, however, this did not seem to be a problem.

On the second or third try, a solution was generally reached that the class was comfortable with. The lecturer then summarised it, and reminded the students that they had to write up the complete answer as an assignment. Roughly half a lecture 
was then spent debriefing the students: explaining some of the issues that had been glossed over in writing the notes, and pointing out some of the unresolved problems of star and planet formation.

Once the exercise was completed, students were given the full set of seven briefing papers, and required to write up the full theory of solar system formation as an assignment. These were marked and returned to the students, allowing the correction of any mistaken ideas the students had accumulated.

\subsection{Good Points of the Exercise}

The experiment had a variety of beneficial effects.

- The exercise was popular with most students. The courses in which these techniques were trialled scored very highly in end-of-semester student assessment questionnaires. Student comments on the anonymous questionnaires included:

'I enjoyed the interactive approach to the lectures - they make you think about what is happening'

'He (the lecturer) involved the class and made us actively think by explaining things to our neighbours or having class activities which helped reinforce the information'

'The most notable strength of the lectures were the willingness of the lecturer to let us participate in group activities'

- The exercise (including the follow-up lecture) covered the subject matter at least as rapidly as conventional lectures.

- Perhaps the greatest benefit was unexpected: the exercise taught the lecturer what the sticking points in students' understanding of the course were. Many of these sticking points were very basic and quite unexpected (though generally obvious with the benefit of hindsight).

- The exercise palpably changed the classroom dynamics: for the remainder of the semester, the class was noticeably more interactive and friendly even in conventional lectures.

\subsection{Bad Points of the Exercise}

- Many students implicitly assumed that the seven briefing papers were seven jigsaw pieces to be assembled in order. They did not realise that one physical process can occur at multiple points during the star formation process, or that two phenomena can operate in parallel, despite implicit statements requiring this in the briefing papers. When this exercise was run for the second time, the students were warned against this tendency towards linear thinking in the lecture preamble. This seemed to fix the problem.

- The briefing papers contained several 'red herrings': statements which, while true, were not relevant. Students clearly had an implicit faith that anything that was in the notes must be relevant, and so tended to construct convoluted stories of star formation, constructed so as to include all the red herrings. Once again, explicitly warning the students against this tendency in the lecture preamble seemed to fix the problem.

- The exercise took about 75 minutes to run, which did not fit into a single lecture slot. This was a serious problem; when the exercise was resumed in the subsequent lecture, students had lost the thread of the argument and were no longer motivated. Wherever possible, these exercises should be simplified sufficiently that they can be run in a single session. A possible alternative would be to run one of these exercises very slowly, perhaps devoting ten minutes per tutorial to it for a month.

- The lecturers' workload required to prepare this exercise was approximately $50 \%$ more than would have been required for a conventional lecture. With experience in the techniques, however, this might decrease.

\section{Other Role-playing Exercises}

We have run role-playing exercises in a variety of other classes. In this section we summarise these exercises, and the lessons learned from them that are not covered above. Notes for these exercises are also available in the electronic edition of this paper.

\subsection{Collaborative Role-Play: \\ Run-Away Greenhouse Exercise}

The aim of this exercise was to teach first-year astronomy students, with no maths and physics background, about the greenhouse effect. Once again, students were asked to play the roles of experts at an astronomy conference. The topic of the conference was the 'Mystery of Venus': why conditions on Venus are so different from those on Earth, when the masses, radii and distances from the Sun of the two planets are so similar. The subject matter was divided into four sections, covering atmospheric absorption, surface outgassing, radiation flow, etc.

As an experiment, this exercise was run as a collaborative role-play rather than a competitive one. Instead of each group sharing one field of expertise (one briefing paper), each group had four members, and the four members would each have one of the four briefing papers. Thus there was no need for groups to interact with other groups; they could work things out collaboratively amongst themselves to win the game.

A second innovation was to set intermediate questions. After the exercise had been running for about 10 minutes, an intermediate question ('How does the atmospheric composition of an Earth-like 
planet change as you raise its temperature?') was posed on the blackboard, and each group had to take a vote. This was repeated with a second question ('What should you add to a planet's atmosphere to raise its temperature?') five minutes later. The aim of these questions was to keep the discussion on track.

This exercise ran much faster than that described in Section 3, and essentially all groups got the correct answer within 30 minutes. Unfortunately, many students achieved this rapid success by not fully thinking through the issues: groups would quickly work out a 'sort-of-all-right' answer and then stop. The interaction between groups in the competitive exercise seemed to prevent this, leading to a deeper engagement with the material.

\subsection{Third-year Nuclear Physics: Nuclear Configuration Exercise}

This exercise was stimulated by the successful implementation of the exercises in astrophysics. The class in this case was a mainstream physics class at the third-year level with 19 students participating. The required aim was to establish the energy levels, angular momentum and configurations in a nucleus that has three valence particles. The approach and subdivision of tasks was similar to that in the case study (six distinct briefing papers). The problem was a difficult one, and significantly above what had usually been presented to the class in previous years. Some aspects of the exercise had been presented earlier in the lecture course: for example, the students were aware of the shell-model energy levels, collective excitations and gamma-ray multipolarities and their relationship to the angular moment of levels. The students had not previously been exposed to the situation where the states in a nucleus involve the coupling of more than two active particles. The exercise was primarily one of integration, requiring all aspects to be incorporated in order to achieve the correct solution. Based on the experience with the earlier exercises, fewer 'red herrings' were included, and the students were expected to complete the exercise as an assignment and asked to present the final solution a week later.

The student responses to this task mirrored those of the case study. The majority of students completed about $3 / 4$ of the exercise in class, with almost all presenting the correct solution at the end. Pleasingly, several students presented particularly insightful responses and even the slower students demonstrated a good grasp of the principles.

All students thought the exercise worthwhile, and the formal student questionnaire responses at the end of the unit were highly favourable.
The adaptation of the approach was not particularly onerous, with the most challenging aspect being balancing the level of difficulty in each of the briefing papers. This was compounded by the fact that the information required to solve the problem completely (that is, to work out the configurations at high energy and angular momentum) required information that was of little use in solving the rest of the problem.

\subsection{Postgraduate Winter School: Galaxy Formation Exercise}

This exercise was run at the 1998 Harley Wood Winter School (an annual meeting of Australian astronomy graduate students from around the country). The topic of the meeting was galaxy formation and evolution, and around 40 students attended. The role-playing exercise was designed to teach the students about current research on high-redshift galaxies, and about the next generation of telescopes and satellites being planned to study them.

Students were assigned to teams of three, each team being chosen by the student organisers to mix more- and less-experienced students, and students from different institutions (thus serving a secondary function as a social mixer). Each team was given briefing sheets describing a particular proposed instrument, and the science goals (in the study of the high-redshift universe) it can address. The students were told that they were an IAU meeting charged with deciding which instruments should be funded. The exercise was run in two one-hour slots, one at the start of the winter school and one at the end.

Rather than have the lecturer chair the 'meeting', one group of students was appointed as chairs of the IAU meeting. They were given a briefing paper about management techniques, and asked to work out some way of getting a consensus from the meeting.

The students tried a variety of approaches: they wandered around trying to set up consortia, and trying to persuade other teams of the superiority of their techniques, while members of the chairing team tried to identify a consensus, or at least some proposals that could be put to a vote. In the end, the chairing group decided to get each team to give a two-minute presentation, and then a vote was taken, with each team allowed three votes, to ensure that each team did not just vote for their own proposal.

The exercise worked very well, and was described by most participants as the highlight of the winter school. Several students revealed unexpected presentation, negotiation and management skills. 
The only problem was a tendency to focus on the instrument projects rather than the science. This, of course, never happens in the real world ....

\section{Summary}

These exercises are a great deal of fun, for both lecturers and students. They can be inserted easily into existing course structures, and used in a wide variety of subjects and levels. They cover the subject matter at a speed comparable to that of normal lectures, and the lecturer's workload is not unduly onerous. We therefore strongly recommend that you give these methods a try.

Classroom role-playing exercises are not, however, a magical panacea for student apathy: a great deal of care is required in the design and implementation of these sessions. This is also true, however, of conventional lectures. What is lacking is the accumulated experience of how best to design and run these exercises. If you use our exercises, or design your own role-playing exercises, we'd therefore like to hear from you; we will provide a central clearing house for the accumulated wisdom and tips of this technique.

The full texts of all the exercises described in this paper are available from

http://msowww.anu.edu.au/ pfrancis/roleplay.html

\section{Acknowledgments}

We would like to thank Mario Zadnik for motivating us to experiment with non-standard teaching methods, and Kathleen Quinlan and her colleagues at the ANU Centre for Educational Development and Academic Methods (CEDAM) for their support and encouragement. Most of all, we'd like to thank the many students who cheerfully survived these teaching experiments.

\section{References}

Errington, E. 1997, Role-Play, Higher Education Research and Development Society of Australia (HERDASA) Green Guide, 21

Loss, R. D., \& Zadnik, M. G. 1994, Australian \& New Zealand Physicist, 31, 195

Matthews, R. S. 1996, in Teaching on Solid Ground, ed. R. J. Menges, M. Weimer et al. (San Francisco: Jossey-Bass), p. 101

Mazur, E. 1997, Peer Instruction: A User's Manual (Upper Saddle River, NJ: Prentice Hall)

Michaelsen, L. K., Fink, L. D., \& Black, R. H. 1996, in To Improve the Academy, Vol. 15, ed. L. Richline (Stillwater: New Forums Press), p. 31

Ramsden, P. 1992, Learning to Teach in Higher Education (New York: Routledge) 